\title{
BMJ Global Health Changing the norms that drive intimate partner violence: findings from a cluster randomised trial on what predisposes bystanders to take action in Kampala, Uganda
}

Tanya Abramsky, ${ }^{1}$ Tina Musuya, ${ }^{2}$ Sophie Namy, ${ }^{3}$ Charlotte Watts, ${ }^{1}$ Lori Michau ${ }^{3}$

To cite: Abramsky T, Musuya T, Namy $\mathrm{S}$, et al. Changing the norms that drive intimate partner violence: findings from a cluster randomised trial on what predisposes bystanders to take action in Kampala, Uganda. BMJ Glob Health 2018;3:e001109. doi:10.1136/ bmjgh-2018-001109

\section{Handling editor Sanni Yaya}

- Additional material is published online only. To view please visit the journal online (http://dx.doi.org/10.1136/ bmjgh-2018-001109).

Received 13 August 2018 Revised 19 October 2018 Accepted 17 November 2018

A) Check for updates

(c) Author(s) (or their employer(s)) 2018. Re-use permitted under CC BY-NC. No commercial re-use. See rights and permissions. Published by BMJ.

${ }^{1}$ Gender Violence and Health Centre, London School of Hygiene and Tropical Medicine, London, UK

${ }^{2}$ Center for Domestic Violence Prevention, Kampala, Uganda ${ }^{3}$ Raising Voices, Kampala, Uganda

Correspondence to

Tanya Abramsky;

tanya.abramsky@Ishtm.ac.uk

\section{ABSTRACT}

Introduction Despite widespread calls to end violence against women, there remains limited evidence on how to prevent it. Community-level programmes seek to engage all levels of the community in changing norms that drive intimate partner violence (IPV). However, little is known about what predisposes ordinary people to become active in violence prevention.

Methods Using data from the SASA! study, a cluster randomised trial of a community mobilisation intervention in Kampala, Uganda, we explore which community members are most likely to intervene when they witness IPV. A cross-sectional survey of community members (18-49 years) was conducted 4 years after intervention implementation began (2012). Among those who had seen IPV in their community (past year), multivariate logistic regression, disaggregated by sex and trial arm, explored the associations between 'trying to help' and demographics, IPV experience (women)/perpetration (men), childhood abuse experiences, IPV attitudes and SASA! exposure.

Results Overall, SASA! community members were more likely to intervene than their control counterparts $(57 \%$ vs $31 \%$ ). In control communities, older age (women), increasing relationship duration (men), talking to neighbours (men) and believing it is okay for a woman to tell if she is experiencing IPV (men) were positively associated with trying to help. In SASA! communities associated factors were increasing relationship duration (women/men), employment (women), talking to neighbours (women), childhood abuse experiences (women), lifetime IPV (women/men), IPV-related attitudes (women/men) and greater SASA! exposure (women/men)

Conclusions Differing results between intervention and control communities suggest contextual factors may modify the effects of personal characteristics/experiences on helping behaviours. Motivation to act brought about by personal experiences of IPV, for example, might only propel individuals into action if they are equipped with the skills, confidence and support of others to do so. Community mobilisation can help create environments and synergies supportive of action.

Trial registration number NCT00790959.

\section{Key questions}

What is already known?

- Bystander-focused programmes have emerged as a promising form of intervention against violence against women (VAW) among university-based or school-based samples in high-income countries.

- There is very little evidence on bystander behaviour from low-income countries or community-based samples.

What are the new findings?

- SASA!, a community mobilisation intervention to prevent VAW in Kampala, Uganda, made community members more likely to intervene when they witnessed intimate partner violence (IPV).

- In SASA!, although not control communities, in creased bystander action was associated with personal experiences of violence, less personal tolerance of IPV and greater exposure to SASA!

What do the new findings imply?

- Community mobilisation interventions can create environments supportive of bystander action and empower VAW survivors to become active participants in its prevention.

Study protocol Available at http://www.trialsjournal.com/ content/13/1/96.

\section{INTRODUCTION}

Violence against women (VAW) is now widely recognised as a major global public health and human rights problem, with diverse and often profound consequences for physical, mental and social well-being. Male partners are the most common perpetrators of this violence, with $30 \%$ of women worldwide estimated to have experienced physical and/ or sexual intimate partner violence (IPV) at some point in their lives. ${ }^{1}$ 
Despite widespread calls for action to end VAW, there remains limited evidence on what works to prevent it, especially from low-income and middle-income countries, where prevalence is often the highest. ${ }^{2-4}$ Among few promising models that have been subject to rigorous evaluation, several have focused on reducing risk of victimisation or perpetration among small groups of individuals-through group-based participatory education efforts or livelihood programming to change attitudes, promote gender equitable behaviours, promote new models of masculinity, or economically or socially empower women. ${ }^{5-7}$

However, the recent years have seen a growth in programmes that pursue change at a community level. ${ }^{8}$ In recognition of the complex interplay of individual-level, relationship-level, community-level and societal-level factors that shape IPV risk (the 'ecological model'),${ }^{9}$ community mobilisation interventions ${ }^{10} 11$ seek to mobilise entire communities to shift norms and behaviours that underlie and sustain high levels of IPV. Such programmes include strengthening the responses of ordinary community members ('bystanders') to violence in their communities. Although empirical data are scarce, evidence from the USA has shown helpful bystander behaviour to be linked to improved victims' outcomes, including reduced physical injury and better mental health in the longer term. ${ }^{12}{ }^{13}$ The potential for increased bystander action to weaken perceived norms around the acceptability and community tolerance of VAW has also been highlighted. ${ }^{1415}$

We recently reported the results from the SASA! study, a cluster randomised trial (CRT) of a community mobilisation intervention to prevent VAW and reduce HIV risk in Kampala, Uganda. ${ }^{10}$ After 3 years of SASA!, women in intervention communities were $52 \%$ less likely to report past year experience of physical IPV, compared with women in control communities (adjusted risk ratio 0.48, $95 \%$ CI 0.16 to 1.39 ), and the intervention had statistically significant impact on the secondary prevention (cessation) of all forms of IPV (physical, sexual, emotional) where it was previously occurring. ${ }^{16}$ Women in SASA! communities $^{10}$ who had experienced IPV were more likely than their control counterparts to have received an appropriate response from others in their community, a potential mechanism leading to IPV cessation.

Most of what we know about what makes ordinary people intervene when they witness violence comes from research in high-income countries. The main framework for understanding the so-called 'bystander' behaviour, developed by Latané and Darley, ${ }^{17}$ identifies the stages involved in moving to take action-noticing the event, interpreting it as a problem requiring intervention, feeling responsible for dealing with it, deciding on an appropriate response and implementing that response. More recently, an ecological approach to understanding bystander behaviour has emerged, recognising that factors promoting/inhibiting action to prevent violence operate at all levels of the social ecology. ${ }^{18-20}$ Normative factors such as gender-inequitable masculinity norms about sexual interaction, ${ }^{21}{ }^{22}$ pervasive beliefs that violence is a normal part of a relationship and norms of privacy around relationships ${ }^{23}$ have been identified as barriers to action. So too have more pragmatic considerations such as bystanders' concerns about their own safety and bystander uncertainty about whether (or what) intervention is needed. ${ }^{2324}$ Factors shown to encourage bystander intervention include attitudes supportive of helping, ${ }^{25}$ higher self-efficacy and collective efficacy, ${ }^{20} 2526$ knowledge about violence and helpful bystander behaviours, ${ }^{27}$ empathy with the victim, ${ }^{28}$ personal experiences of domestic violence, ${ }^{29}$ strong social support ties to neighbours and community, ${ }^{20}$ and less personal tolerance of IPV. $^{26}$

Findings on the association between a bystander's sex and propensity to intervene are mixed. Some studies have suggested that women are more predisposed to intervene in situations of interpersonal violence, ${ }^{25} 27$ and to take actions such as calling the police ${ }^{3031}$ or providing emotional support to victims. ${ }^{32}$ Men, however, are more likely to intervene physically ${ }^{33}$ or talk directly to the abuser. ${ }^{30}$ Structural barriers to intervening may also differ by sex. For example, research in rural Uganda found that women fear greater repercussions than men if they report IPV occurring in their communities-they may be branded a gossip and consequently suffer violence themselves. ${ }^{34}$

In recognition of the many barriers to action, recent years have seen 'bystander focused' interventions, which aim to change the attitudes and strengthen the capacity of potential bystanders, emerge as a promising type of intervention against various forms of violence. ${ }^{35}$ Although few have been subject to rigorous evaluation, and some have shown no (or only short-term) impact on actual bystander behaviours, ${ }^{36}$ several programmes have been demonstrated to promote positive bystander intentions $^{37} 38$ and behaviours, ${ }^{39}$ and in some cases prevent violence. ${ }^{39-43}$ Effective approaches tend to be those that are theoretically driven, implemented over a sufficient time period (not 'one off' sessions), and that combine bystander education (to engender a community of responsibility and build skills on how to intervene effectively and safely) with components to address social norms relating to sexual interaction, violence and masculinity. ${ }^{153543}$

Most studies into bystander behaviour, however, are conducted in high-income countries and among university-based or school-based samples. There is very little research on this topic from low-income countries, nor (with few exceptions) ${ }^{20}$ on what promotes bystander intervention in the general community or within the context of a broader community intervention.

This paper uses data from the SASA! study to address some of these evidence gaps and further explore the role of community members in IPV prevention and response, both within and outside the context of a holistic community intervention. We present data on 
how often community members witness or hear IPV in their communities and explore which individual-level characteristics are associated with whether or not they try to help. We explore relationships separately for men and women, and for intervention and control communities.

\section{METHODS}

\section{Study setting}

The SASA! study was conducted between November 2007 and May 2012 in Kampala, Uganda. At the outset of the study, $44 \%$ of ever-partnered women aged 18-49 reported having ever experienced physical and or/sexual IPV. Patriarchal norms were prevalent, with $25 \%$ of men and $58 \%$ of women reporting attitudes accepting of a man's use of violence against his wife.

\section{The SASA! intervention}

The SASA! Activist Kit for Preventing Violence against Women and $H I V^{44}$ is a community mobilisation intervention seeking to change community norms and behaviours that result in gender inequality, violence and increased HIV vulnerability for women. It was developed by Raising Voices (http://raisingvoices.org/) and implemented in Kampala by the Center for Domestic Violence Prevention ().

The SASA! approach draws heavily on two theoretical frameworks: the ecological model (discussed above), and the stages of change theory which identifies key stages involved in individual-level behaviour change. ${ }^{45}$ SASA! seeks to change individuals' attitudes, community norms and structures by supporting entire communities through a phased process of change. SASA!, meaning 'Now' in Kiswahili, is an acronym for the four phases of the approach-Start, Awareness, Support, Action. The intervention focuses on promoting a critical analysis and discussion of power and power inequalities-with an emphasis on men's power over women and how it fuels VAW, as well as ways in which people can use their power positively to create change at an individual and community level.

In the Start phase, community activists (CAs) (regular women and men interested in issues of violence, power and rights) are selected and given (ongoing) training to sensitise them to the issues of VAW and enable them to work through the subsequent phases of SASA! within their communities. In the Awareness phase, CAs form a core part of SASA!, conducting frequent and diverse activities within their own social networks, to engage and support activism among their families, friends, colleagues and neighbours. SASA! also works with service providers (eg, police and healthcare workers) and opinion leaders such as clan, traditional, local government and religious leaders. Training, one-on-one support and mentoring support them to become effective advocates for women's rights within their communities, enhance their knowledge and skills to prevent and respond to VAW, help them build connections and referral networks with other service providers, and encourage them to use existing/ develop new local or national laws as redress when appropriate.

The Support and Action phases help communities move from improved awareness about violence into actual and sustained action to prevent it. Key activities focus on making it a responsibility of every individual (and institution) to support women experiencing/men using violence, challenging the notion that to intervene is to meddle in private matters. They emphasise that men who use violence should be held accountable for their actions. In line with this, SASA! activities (1) promote awareness that violence is never acceptable, that it has negative consequences for everyone and that women experiencing violence are not to blame for it; (2) ensure that those using violence know that it is their choice and they are responsible for it; (3) strengthen community members' confidence and skills to become violence prevention activists; (4) educate community members on how to intervene when violence occurs (either in real time or after depending on when it is safe for them to do so) and help survivors of violence in a manner that upholds their rights, autonomy and safety; (5) share referral information that community members can use to support women who need help; and (6) help service providers formalise any changes they have made to better respond to and prevent VAW.

\section{Trial design}

The evaluation design is described in detail elsewhere. ${ }^{1046}$ Briefly, we conducted a pair-matched CRT involving eight communities (four intervention, four control), each comprising one or two administrative parishes. Two cross-sectional surveys of community members (18-49 years who had lived in the community for at least a year) were carried out, one prior to intervention implementation and one 4 years later. Households were randomly sampled from enumeration areas within intervention and comparable control zones, with one eligible member randomly selected from each sampled household (for reasons of respondent safety). Baseline data indicated a high level of comparability between intervention and control communities prior to intervention implementation (online supplementary file 1).

The study was conducted in accordance with the WHO guidelines for the safe and ethical collection of data on VAW. ${ }^{47}$ All respondents provided written informed consent and were interviewed in a safe and private place of their choosing.

\section{Outcomes and exposures}

This secondary analysis uses data from the follow-up survey on male and female community members' responses to IPV in their communities. Among respondents who answered 'yes' to having seen or heard violence happening between partners in their community in the past 12 months $(n=1570,62 \%$ of the sample $)$, the 


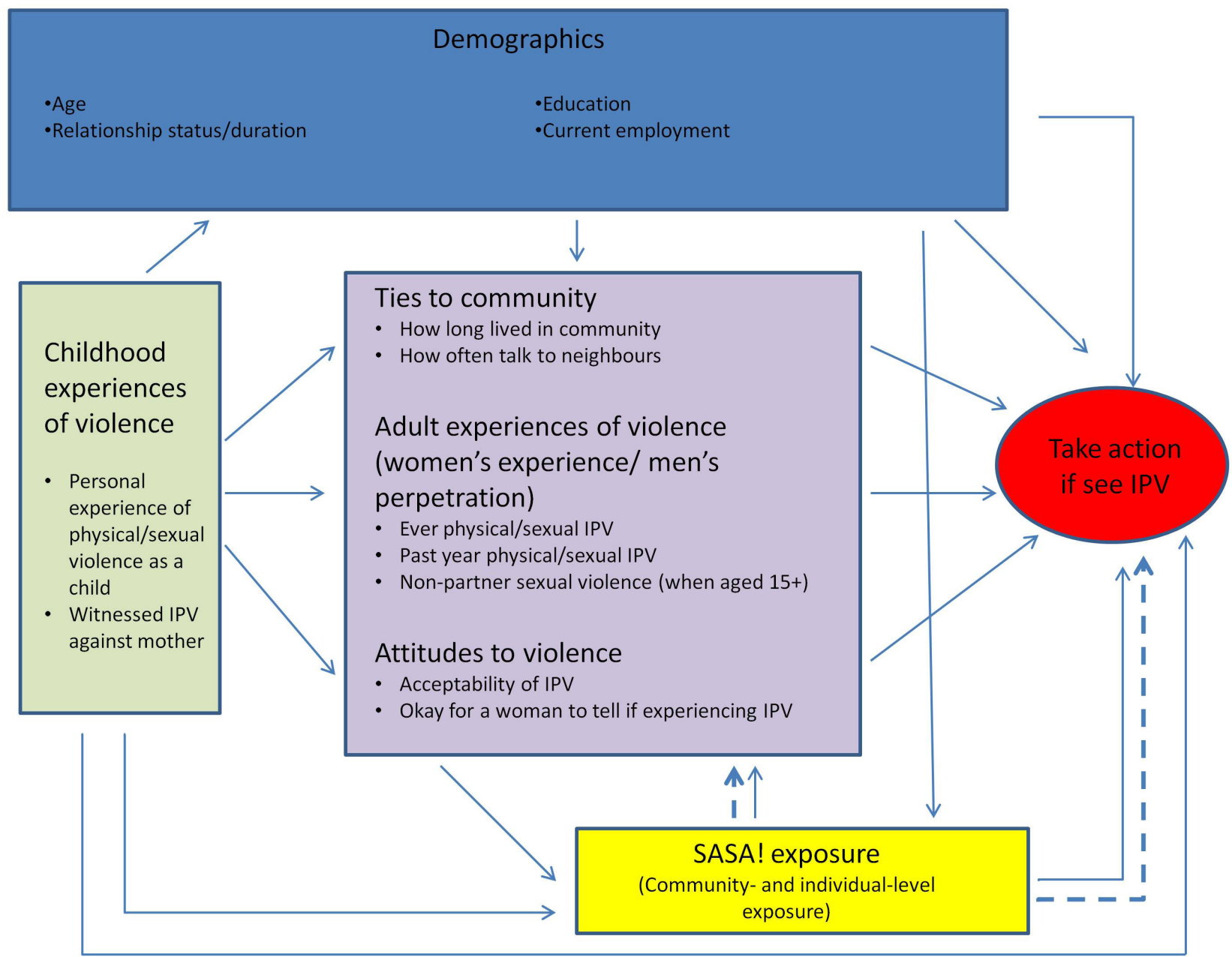

Figure 1 Conceptual framework outlining hypothesised individual-level influences on community members' propensity to take action if they see/hear intimate partner violence (IPV) in their community.

outcome was measured with the question 'Did you do something to try to help?' (yes/no).

While acknowledging the importance of all levels of the social ecology in shaping IPV risk and community members' propensities to intervene, ${ }^{9}{ }^{19}$ this paper focuses on bystander characteristics (ie, who is most likely to intervene). However, we also explore how associations between bystander characteristics and helping behaviours may be modified in the context of a community mobilisation intervention.

Factors considered as potential determinants of the outcome (figure 1) were demographics (age, relationship status/duration, education, current employment status); ties to the community (length of time living in the community, how often they talk to neighbours); personal experiences of IPV and childhood abuse (ever and past year physical/sexual IPV, witnessed IPV against mother as a child, badly beaten by parents as a child, experienced child sexual abuse [CSA]); attitudes (attitudes supportive of wife-beating, believing it is okay for a woman to tell others if she is experiencing IPV); and (in SASA! communities only) individual-level degree of exposure to the SASA! intervention.

Questions on IPV (measuring specific acts) were based on those used in the WHO Multi-country Study on Women's Health and Domestic Violence. ${ }^{48}$ For women we measured experiences of these acts by their partner, while for men we measured perpetration against their partner. Due to the potential for major under-reporting of violence among men, especially in intervention communities, we measured past year perpetration with an anonymous card administered at the end of the interview. Respondents were asked to put a mark next to a sad picture 'if you have hurt your partner either physically or sexually in the last 12 months' (and next to a happy face if not), and place the card in a sealed envelope so the interviewer could not see the answer (online supplementary file 2 provides detail on all exposures/outcome).

\section{Statistical analysis}

The analysis was performed separately for men and women and for intervention and control communities, as we hypothesised that factors influencing whether or not 
someone tried to help might differ by sex and be modified by exposure to SASA!. We used logistic regression to model crude associations between each exposure variable and the outcome, adjusting for community as a fixed effect. Clustered sandwich variance estimators were used to account for intracluster correlation at the enumeration area level. We then conducted multivariate logistic regression. Factors were considered for inclusion in the multivariate analysis if they were associated $(\mathrm{p}<0.05)$ with trying to help in any of the crude models (men/ women, control/SASA!). We included just one indicator of childhood experiences of abuse (a composite of the three abuse-related variables) and one of adult experience/perpetration of violence (based on the strength of associations in the crude models and prevalence of the exposures). This was done to minimise collinearity in the adjusted models. Based on our conceptual framework (figure 1), we added variables to the model sequentially, so that we could estimate the association between more distal exposures and the outcome without attenuation by variables potentially on the causal pathway between the two. Variables were added as follows: demographic factors (model 1); + the indicator of childhood exposure to violence (the exposure chronologically most distal to the outcome) (model 2); + the more proximate exposures (indicators of ties to the community, attitudes relating to IPV and experience/perpetration of IPV in adulthood) (model 3). In the final model (model 4), we added the individual-level SASA! dose variable.

The same set of variables was included in the models for men and women and for control and SASA! communities to allow direct comparisons between the results. Analyses were performed using Stata SE V.14.

\section{RESULTS}

There were 2532 respondents interviewed in the follow-up survey (1130 women, 1402 men), representing a 99\% response rate (online supplementary file 3). Approximately half of women and more than two-thirds of men (overall) had witnessed IPV happening in their community, with figures higher in control compared with SASA! communities (tables 1 and 2). Where IPV was observed, those in SASA! communities were much more likely to report having tried to help (about one-third of men and women in control communities, vs over half in SASA! communities).

\section{Women}

\section{Demographics}

In both SASA! and control communities, older women were more likely to report having helped than younger women, although after adjustment for other demographics (model 1) this association remained in control communities only. In SASA!, although not control communities, women who had been in long-standing relationships were more likely to report having helped than those in newer (or no) relationships, even after adjustment (model 1). Completed primary education was not associated with helping behaviours in SASA! or control communities (tables 1 and 3). In SASA! communities only,

\section{Ties to the community}

Across all communities, women who had lived in their community for at least 4 years were more likely to report having helped than women who had arrived in the community more recently, although this association did not remain in the multivariate model (model 3). Those who talked to neighbours at least once a week were more likely to report helping than those who never/rarely spoke to them. However, after adjustment for other variables (model 3), this association remained significant only in SASA! communities.

\section{Personal experiences of violence}

Associations between personal experiences of violence and having tried to help differed between SASA! and control communities.

In SASA! communities, women who had ever experienced physical/sexual IPV were more likely to report having helped than those with no lifetime experience of IPV (model 3). Past year experience of physical/sexual IPV was also associated with an increased propensity to help, although the association was not statistically significant. Women who had witnessed their mother being beaten by their father, had been badly beaten by their parents as a child, had experienced CSA or had experienced non-partner sexual violence since the age of 15 were also more likely to report having helped compared with women without these experiences. Childhood experiences of abuse remained a predictor of helping behaviour after adjustment for demographic variables (model 2), although not surprisingly, weakened once variables potentially on the pathway between childhood experiences and later helping behaviours were added (model 3).

In contrast, in control communities, with the exception of CSA, a woman's own experiences of violence were not associated with having tried to help.

\section{Attitudes}

In SASA! communities, a woman's propensity to intervene was strongly associated with her own attitudes about VAW. Women were more likely to report having helped if they believed it was never justified for a husband to beat his wife, or that it was okay for a woman to tell others if she was experiencing IPV (model 3). These associations were much weaker (and not statistically significant) in control communities.

\section{Exposure to SASA!}

Within SASA! communities, a strong dose-response relationship was observed between women's exposure to SASA! and their propensity to try to help (model 4). 
Table 1 Factors associated with women trying to help when they see/hear IPV in their communities

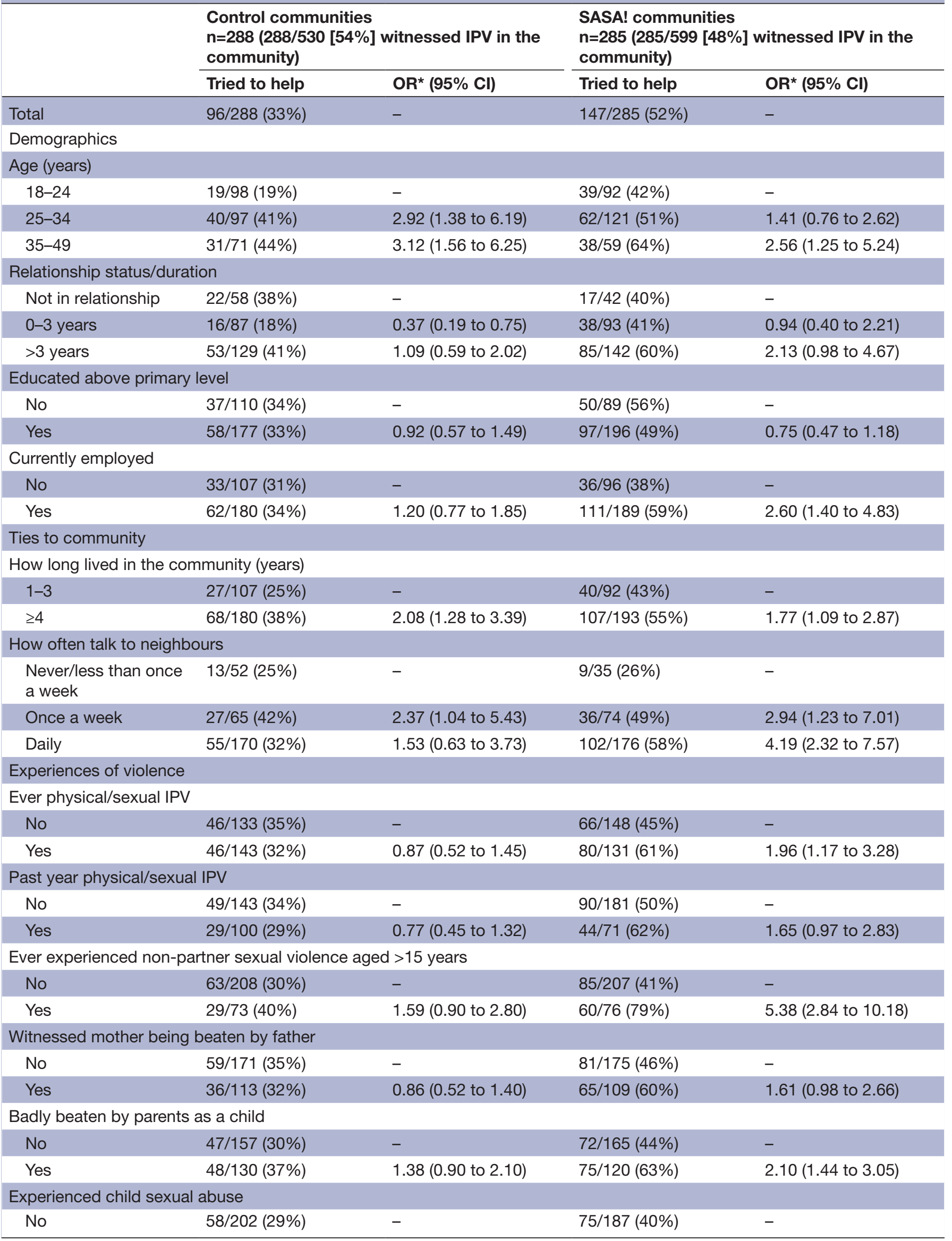




\begin{tabular}{|c|c|c|c|c|}
\hline & \multicolumn{2}{|c|}{$\begin{array}{l}\text { Control communities } \\
\mathrm{n}=288 \text { ( } 288 / 530[54 \%] \text { witnessed IPV in the } \\
\text { community) }\end{array}$} & \multicolumn{2}{|c|}{$\begin{array}{l}\text { SASA! communities } \\
n=285 \text { ( } 285 / 599[48 \%] \text { witnessed IPV in the } \\
\text { community) }\end{array}$} \\
\hline & Tried to help & $\mathrm{OR}^{\star}(95 \% \mathrm{Cl})$ & Tried to help & $\mathrm{OR}^{*}(95 \% \mathrm{Cl})$ \\
\hline Yes & $38 / 86(44 \%)$ & $1.92(1.10$ to 3.36$)$ & $72 / 98(73 \%)$ & 4.17 (2.39 to 7.27$)$ \\
\hline \multicolumn{5}{|c|}{ Any abuse-related experience as a child (composite: witnessed IPV, badly beaten or CSA) } \\
\hline No & $29 / 101(29 \%)$ & - & $37 / 96(39 \%)$ & - \\
\hline Yes & $66 / 185(36 \%)$ & $1.34(0.68$ to 2.65$)$ & $110 / 189(58 \%)$ & $2.18(1.30$ to 3.64$)$ \\
\hline \multicolumn{5}{|l|}{ Attitudes } \\
\hline \multicolumn{5}{|c|}{ Attitudes supportive of wife-beating } \\
\hline No & $40 / 102(39 \%)$ & - & $114 / 184(62 \%)$ & - \\
\hline Yes & $54 / 184(29 \%)$ & $0.67(0.42$ to 1.06$)$ & $33 / 101(33 \%)$ & $0.27(0.14$ to 0.51$)$ \\
\hline \multicolumn{5}{|c|}{ Believes okay for a woman to tell if experiencing IPV } \\
\hline No & $41 / 135(31 \%)$ & - & $17 / 63(27 \%)$ & - \\
\hline Yes & $54 / 152(36 \%)$ & $1.27(0.78$ to 2.05$)$ & $130 / 222(59 \%)$ & $3.69(1.79$ to 7.61$)$ \\
\hline \multicolumn{5}{|l|}{ SASA! exposure } \\
\hline \multicolumn{5}{|c|}{ Reported exposure to SASA! } \\
\hline None & NA & NA & 23/76 (30\%) & - \\
\hline Low/moderate & NA & NA & $53 / 119(45 \%)$ & $1.79(1.16$ to 2.76$)$ \\
\hline High & NA & NA & $71 / 90(79 \%)$ & 8.52 (3.27 to 22.20$)$ \\
\hline
\end{tabular}

*Adjusted for community as a fixed effect. SE calculated using cluster robust option.

CSA, child sexual abuse; IPV, intimate partner violence; NA, not applicable.

\section{Men}

Demographics

In both SASA! and control communities, men over 25 years of age were more likely to report helping than younger men, although this association weakened after adjustment for other demographics (model 1). Men in long-standing relationships were more likely to report having helped than those in newer relationships, an association that persisted in multivariate models. Education was not associated with having tried to help in either SASA! or control communities. In control (although not SASA!) communities, men who were currently employed were more likely than those not working to report having helped (tables 2 and 4).

\section{Ties to community}

In SASA! communities only, men who had lived in the community for at least 4 years were slightly more likely to report having helped than men who had arrived in the community more recently, although this association lost statistical significance in the multivariate analysis (model 3). In control communities only, men were substantially more likely to report having helped the more often they talked to their neighbours, an association that did not quite attain statistical significance but retained its magnitude in the multivariate model (model 3).

\section{Personal experiences of violence}

As with women, associations between personal history of violence and having tried to help were different for SASA! and control communities.

In SASA! communities, men who had ever perpetrated physical/sexual IPV were more likely to report having helped than those with no lifetime history of perpetration (model 3). Past year perpetration of IPV was not, however, associated with trying to help. Men who had witnessed their mother being beaten by their father, had been badly beaten by their parents as a child or had experienced CSA were also more likely to report having helped compared with men without these experiences. The association between childhood experiences of abuse and trying to help did not quite attain statistical significance, although was not attenuated by the inclusion of demographic variables in the multivariate analysis (model 2).

In control communities, neither a man's personal history of IPV perpetration nor his childhood experiences of abuse were associated with having tried to help.

\section{Attitudes}

In both SASA! and control communities, a man's propensity to intervene was associated with his own attitudes about VAW. Men were more likely to report having helped if they believed it was never justified for a husband to beat his wife or that it was okay for a woman to tell others if she 
Table 2 Factors associated with men trying to help when they see/hear IPV in their communities

\begin{tabular}{|c|c|c|c|c|}
\hline & \multicolumn{2}{|c|}{$\begin{array}{l}\text { Control communities } \\
n=503(503 / 634[79 \%] \text { witnessed IPV in } \\
\text { community) }\end{array}$} & \multicolumn{2}{|c|}{$\begin{array}{l}\text { SASA! communities } \\
\mathrm{n}=494 \text { (494/768 [64\%] witnessed IPV in } \\
\text { community) }\end{array}$} \\
\hline & Tried to help & $\mathrm{OR}^{*}(95 \% \mathrm{Cl})$ & Tried to help & $\mathrm{OR}^{*}(95 \% \mathrm{Cl})$ \\
\hline Total & $152 / 503(30 \%)$ & - & $295 / 494(60 \%)$ & - \\
\hline \multicolumn{5}{|l|}{ Demographics } \\
\hline \multicolumn{5}{|l|}{ Age (years) } \\
\hline $18-24$ & 28/142 (20\%) & - & $87 / 175(50 \%)$ & - \\
\hline $25-34$ & 72/192 (38\%) & $2.32(1.42$ to 3.78$)$ & $130 / 203(64 \%)$ & $1.74(1.02$ to 2.94$)$ \\
\hline $35-49$ & $50 / 143(35 \%)$ & 2.18 (1.23 to 3.87$)$ & 73/105 (70\%) & 2.20 (1.03 to 4.69$)$ \\
\hline \multicolumn{5}{|c|}{ Relationship status/duration } \\
\hline Not in relationship & $16 / 114(14 \%)$ & - & $39 / 83(47 \%)$ & - \\
\hline $0-3$ years & $58 / 192(30 \%)$ & 2.67 (1.61 to 4.43$)$ & $120 / 216(56 \%)$ & 1.48 (0.92 to 2.39$)$ \\
\hline$>3$ years & $74 / 179(41 \%)$ & 4.15 (2.30 to 7.49$)$ & 130/187 (70\%) & 2.65 (1.72 to 4.09$)$ \\
\hline \multicolumn{5}{|c|}{ Educated above primary level } \\
\hline No & $41 / 140(29 \%)$ & - & $84 / 137(61 \%)$ & - \\
\hline Yes & $111 / 363(31 \%)$ & 1.13 (0.64 to 2.02) & $211 / 357$ (59\%) & 0.88 (0.56 to 1.38$)$ \\
\hline \multicolumn{5}{|l|}{ Currently employed } \\
\hline No & $8 / 51(16 \%)$ & - & $33 / 55(60 \%)$ & - \\
\hline Yes & $144 / 452(32 \%)$ & 2.51 (1.24 to 5.07$)$ & $262 / 439(60 \%)$ & $1.01(0.57$ to 1.80$)$ \\
\hline \multicolumn{5}{|l|}{ Ties to community } \\
\hline \multicolumn{5}{|c|}{ How long lived in the community (years) } \\
\hline $1-3$ & $32 / 123(26 \%)$ & - & $54 / 108(50 \%)$ & - \\
\hline$\geq 4$ & $120 / 380(32 \%)$ & $1.36(0.82$ to 2.26$)$ & $241 / 386(62 \%)$ & 1.68 (1.07 to 2.63$)$ \\
\hline \multicolumn{5}{|c|}{ How often talk to neighbours } \\
\hline $\begin{array}{l}\text { Never/less than once } \\
\text { a week }\end{array}$ & $7 / 47$ (15\%) & - & $18 / 30(60 \%)$ & - \\
\hline Once a week & $47 / 157(30 \%)$ & $2.12(0.80$ to 5.62$)$ & $61 / 122(50 \%)$ & 0.66 (0.28 to 1.58$)$ \\
\hline Daily & 98/299 (33\%) & $2.42(0.98$ to 5.96$)$ & $216 / 342(63 \%)$ & 1.09 (0.57 to 2.09) \\
\hline \multicolumn{5}{|l|}{$\begin{array}{l}\text { Perpetration/ } \\
\text { experiences of } \\
\text { violence }\end{array}$} \\
\hline \multicolumn{5}{|c|}{ Ever perpetrated physical/sexual IPV } \\
\hline No & $53 / 155(34 \%)$ & - & $174 / 313(56 \%)$ & - \\
\hline Yes & $92 / 301(31 \%)$ & $0.96(0.68$ to 1.36$)$ & $101 / 136(74 \%)$ & 2.43 (1.55 to 3.79$)$ \\
\hline \multicolumn{5}{|c|}{ Perpetrated IPV in past year } \\
\hline No & 64/201 (32\%) & - & 198/316 (63\%) & - \\
\hline Yes & $76 / 227(33 \%)$ & 1.05 (0.70 to 1.56$)$ & $64 / 101(63 \%)$ & 1.09 (0.51 to 2.34$)$ \\
\hline \multicolumn{5}{|c|}{ Witnessed mother being beaten by father } \\
\hline No & $68 / 207(33 \%)$ & - & $147 / 268(55 \%)$ & - \\
\hline Yes & $84 / 296(28 \%)$ & $0.80(0.59$ to 1.08$)$ & $146 / 224(65 \%)$ & $1.52(1.19$ to 1.96$)$ \\
\hline \multicolumn{5}{|c|}{ Badly beaten by parents as a child } \\
\hline No & $88 / 263(33 \%)$ & - & $147 / 271(54 \%)$ & - \\
\hline Yes & $64 / 240(27 \%)$ & $0.76(0.49$ to 1.19$)$ & $148 / 223(66 \%)$ & 1.59 (0.87 to 2.90$)$ \\
\hline \multicolumn{5}{|c|}{ Experienced child sexual abuse } \\
\hline No & $128 / 443(29 \%)$ & - & $272 / 461(59 \%)$ & - \\
\hline Yes & $23 / 57(40 \%)$ & 1.58 (0.89 to 2.80$)$ & 23/32 (72\%) & $1.97(0.85$ to 4.59$)$ \\
\hline
\end{tabular}




\begin{tabular}{|c|c|}
\hline $\begin{array}{l}\text { Control communities } \\
\mathrm{n}=503 \text { (503/634 }[79 \%] \text { witnessed IPV in } \\
\text { community) }\end{array}$ & $\begin{array}{l}\text { SASA! communities } \\
\mathrm{n}=494 \text { (494/768 [64\%] witnessed IPV in } \\
\text { community) }\end{array}$ \\
\hline $\mathrm{OR}^{\star}(95 \% \mathrm{Cl})$ & $\mathrm{OR}^{\star}(95 \% \mathrm{Cl})$ \\
\hline
\end{tabular}

\begin{tabular}{|c|c|c|c|c|}
\hline \multicolumn{5}{|c|}{ Any abuse-related experience as a child (composite: witnessed IPV, badly beaten or CSA) } \\
\hline No & $46 / 137(34 \%)$ & - & $96 / 183(52 \%)$ & - \\
\hline Yes & $106 / 366(29 \%)$ & $0.77(0.54$ to 1.12$)$ & $199 / 310(64 \%)$ & $1.57(0.95$ to 2.60$)$ \\
\hline \multicolumn{5}{|c|}{ Attitudes } \\
\hline \multicolumn{5}{|c|}{ Attitudes supportive of wife-beating } \\
\hline No & $29 / 65(45 \%)$ & - & $231 / 371(62 \%)$ & - \\
\hline Yes & $123 / 438(28 \%)$ & 0.53 (0.30 to 0.93$)$ & 64/123 (52\%) & 0.75 (0.44 to 1.27$)$ \\
\hline
\end{tabular}

Believes okay for a woman to tell if experiencing IPV

\begin{tabular}{|c|c|c|c|c|}
\hline No & $76 / 307(25 \%)$ & - & $20 / 50(40 \%)$ & - \\
\hline Yes & 76/196 (39\%) & 1.70 (1.20 to 2.41$)$ & $275 / 444(62 \%)$ & 2.19 (1.09 to 4.39$)$ \\
\hline \multicolumn{5}{|l|}{ SASA! exposure } \\
\hline \multicolumn{5}{|c|}{ Reported exposure to SASA! } \\
\hline None & NA & NA & $11 / 47$ (23\%) & - \\
\hline Low/moderate & NA & NA & $154 / 264(58 \%)$ & 4.42 (2.11 to 9.24$)$ \\
\hline High & NA & NA & 130/183 (71\%) & 7.67 (3.72 to 15.82$)$ \\
\hline
\end{tabular}

*Adjusted for community as a fixed effect. SEs calculated using cluster robust option. Women who were currently employed (mostly informal employment) were more likely than those not working to report having helped someone (model 1).

CSA, child sexual abuse; IPV, intimate partner violence; NA, not applicable.

was experiencing IPV. However, the association remained significant only for the latter belief in the multivariate analysis (model 3).

\section{Exposure to SASA!}

Within SASA! communities men with increasing SASA! exposure were more likely than those with less/no exposure to report having helped (model 4).

\section{DISCUSSION}

Our analysis shows that a high proportion of respondents had witnessed IPV in their communities, and that those in SASA! communities were more likely than their control counterparts to report having tried to help. Our findings also highlight several characteristics that are associated with an increased propensity to intervene when a person witnesses IPV in their community. Most noteworthy is that factors associated with trying to help differ markedly between SASA! and control communities, with a greater number of predisposing factors identified in SASA! communities.

In control communities, the main factors associated with trying to help were demographic factors (age for women, duration of relationship for men). Ties to the community and believing that it is okay for a woman to tell if she is experiencing IPV were also associated with men's propensity to help in control communities. While the perceived wisdom is that programmes have more success changing attitudes and reducing perpetration among younger men in newer relationships where gender norms, relationship expectations and roles are less firmly entrenched, this result points to the wider value (in terms of other behavioural outcomes) of working with men in more long-standing relationships.

In SASA! communities, several additional factors were associated with taking action. Among both women and men, lifetime experience/perpetration of IPV was strongly related to propensity to intervene. This association weakened very slightly once individual-level SASA! exposure was added into the model, unsurprising if those involved in IPV respond more readily to SASA! ideas and engage more frequently in SASA! activities (thereby increasing propensity to intervene). Childhood experiences of abuse were also strongly related to helping behaviours among women and somewhat associated among men. We hypothesise that those affected by violence as children and/or in adulthood may feel more empathy with others experiencing (or perpetrating) IPV ${ }^{49}$ increasing their motivation to act, ${ }^{14}$ and have greater knowledge of what kind of action is likely to be welcomed and helpful.

We offer two reasons why an association between IPV experience/perpetration and trying to help was observed in SASA! but not control communities. First, in line with Latané and Darley's ${ }^{17}$ identified stages for bystander action, increased empathy and motivation to act might only lead to actual action if a person feels a sense of responsibility to act and has the confidence and skills with which to do so. SASA!'s phased process of community 
Table 3 Multivariate models of factors associated with women trying to help when they see/hear IPV in their communities

Control communities

Model $1 \%$

$\mathrm{OR}^{\star}(95 \% \mathrm{Cl}) \quad \mathrm{OR}^{\star}(95 \% \mathrm{Cl})$

SASA! communities

\section{SASA! communities}

Model 3 Model $1 \quad$ Model 2

$\mathrm{OR}^{\star}(95 \% \mathrm{Cl}) \quad \mathrm{OR}^{\star}(95 \% \mathrm{Cl})$

Model 3

Model 4

$\mathrm{OR}^{\star}(95 \% \mathrm{Cl})$

$O R^{\star}(95 \% \mathrm{Cl})$

$\mathrm{OR}^{\star}(95 \% \mathrm{Cl})$

\section{Demographics \\ Age (years)}

\begin{tabular}{lllllllll}
$18-24$ & - & - & - & - & - & - & - \\
\hline $25-34$ & $2.53(1.05$ to & $2.40(0.94$ to & $2.44(0.96$ to & $0.86(0.41$ to & $0.78(0.38$ to & $0.71(0.32$ to & $0.76(0.31$ to \\
& $6.09)$ & $5.94)$ & $6.20)$ & $1.80)$ & $1.61)$ & $1.58)$ & $1.88)$ \\
\hline $35-49$ & $2.61(1.15$ to & $2.41(1.03$ to & $2.06(0.84$ to & $1.33(0.57$ to & $1.20(0.51$ to & $1.06(0.42$ to & $1.17(0.40$ to \\
& $5.94)$ & $5.68)$ & $5.05)$ & $3.11)$ & $2.84)$ & $2.73)$ & $3.45)$
\end{tabular}

Relationship duration

$\begin{array}{llllllll}\begin{array}{l}\text { Not in } \\ \text { relationship }\end{array} & - & - & - & - & - & - & - \\ \text { 0-3 years } & 0.46(0.23 \text { to } & 0.45(0.22 \text { to } & 0.54(0.27 \text { to } & 1.06(0.43 \text { to } & 1.13(0.45 \text { to } & 0.92(0.31 \text { to } & 0.71(0.26 \text { to } \\ & 0.94) & 0.92) & 1.11) & 2.58) & 2.80) & 2.76) & 1.93) \\ \text { >3 years } & 0.97(0.51 \text { to } & 0.97(0.50 \text { to } & 1.01(0.51 \text { to } & 2.20(1.04 \text { to } & 2.49(1.10 \text { to } & 2.16(0.92 \text { to } & 1.73(0.70 \text { to } \\ & 1.84) & 1.89) & 2.00) & 4.66) & 5.66) & 5.06) & 4.28)\end{array}$

Currently employed

$\begin{array}{lllllllll}\text { No } & - & - & - & - & - & - & - \\ \text { Yes } & 0.84(0.45 \text { to } & 0.85(0.46 \text { to } & 0.75(0.40 \text { to } & 2.51(1.22 \text { to } & 2.44(1.14 \text { to } & 2.80(1.28 \text { to } & 2.63(1.23 \text { to } \\ & 1.54) & 1.58) & 1.40) & 5.16) & 5.26) & 6.12) & 5.65)\end{array}$

Childhood experiences of abuse

Any abuse related experience as a child (witnessed IPV, badly beaten or CSA)

$\begin{array}{llllll}\text { No } & - & - & - & - & - \\ \text { Yes } & 1.15(0.55 \text { to } & 1.20(0.57 \text { to } & 2.21(1.20 \text { to } & 1.66(0.87 \text { to } & 1.73(0.89 \text { to } \\ & 2.44) & 2.53) & 4.05) & 3.15) & 3.34)\end{array}$

Ties to community

How long lived in the community (years)

\begin{tabular}{|c|c|c|c|}
\hline $1-3$ & - & - & - \\
\hline$\geq 4$ & $\begin{array}{l}1.64 \text { (0.93 to } \\
2.89)\end{array}$ & $\begin{array}{l}0.98(0.57 \text { to } \\
1.70)\end{array}$ & $\begin{array}{l}0.88 \text { (0.48 to } \\
1.61)\end{array}$ \\
\hline \multicolumn{4}{|c|}{ How often talk to neighbours } \\
\hline $\begin{array}{l}\text { Never/less } \\
\text { than once a } \\
\text { week }\end{array}$ & - & - & - \\
\hline Once a week & $\begin{array}{l}1.82(0.64 \text { to } \\
5.18)\end{array}$ & $\begin{array}{l}2.86(0.97 \text { to } \\
8.45)\end{array}$ & $\begin{array}{l}2.62(1.01 \text { to } \\
6.82)\end{array}$ \\
\hline Daily & $\begin{array}{l}1.00(0.40 \text { to } \\
2.50)\end{array}$ & $\begin{array}{l}4.10 \text { (2.01 to } \\
8.35)\end{array}$ & $\begin{array}{l}2.47 \text { (1.03 to } \\
5.94)\end{array}$ \\
\hline \multicolumn{4}{|c|}{ Adult experiences of violence } \\
\hline \multicolumn{4}{|c|}{ Ever experienced physical/sexual IPV } \\
\hline No & - & - & - \\
\hline Yes & $\begin{array}{l}0.79 \text { (0.42 to } \\
1.47)\end{array}$ & $\begin{array}{l}2.05 \text { (1.06 to } \\
3.96)\end{array}$ & $\begin{array}{l}1.67(0.85 \text { to } \\
3.25)\end{array}$ \\
\hline \multicolumn{4}{|l|}{ Attitudes } \\
\hline \multicolumn{4}{|c|}{ Attitudes supportive of wife-beating } \\
\hline No & - & - & - \\
\hline Yes & $\begin{array}{l}0.71 \text { ( } 0.46 \text { to } \\
1.11)\end{array}$ & $\begin{array}{l}0.25 \text { ( } 0.12 \text { to } \\
0.55)\end{array}$ & $\begin{array}{l}0.28(0.13 \text { to } \\
0.60)\end{array}$ \\
\hline
\end{tabular}

Continued 
Table 3 Continued

\begin{tabular}{|c|c|c|c|c|c|c|c|}
\hline & \multicolumn{3}{|c|}{ Control communities } & \multicolumn{4}{|c|}{ SASA! communities } \\
\hline & $\begin{array}{l}\text { Model } 1 \\
\text { OR* }(95 \% \mathrm{Cl})\end{array}$ & $\begin{array}{l}\text { Model } 2 \\
\text { OR* }^{\star}(95 \% \mathrm{Cl})\end{array}$ & $\begin{array}{l}\text { Model } 3 \\
\text { OR }^{\star}(95 \% \mathrm{Cl})\end{array}$ & $\begin{array}{l}\text { Model } 1 \\
\text { OR* }(95 \% \mathrm{Cl})\end{array}$ & $\begin{array}{l}\text { Model } 2 \\
\text { OR* }(95 \% \mathrm{Cl})\end{array}$ & $\begin{array}{l}\text { Model } 3 \\
\text { OR }^{\star}(95 \% \mathrm{Cl})\end{array}$ & $\begin{array}{l}\text { Model } 4 \\
\text { OR* }^{\star}(95 \% \mathrm{Cl})\end{array}$ \\
\hline No & & & - & & & - & - \\
\hline Yes & & & $\begin{array}{l}1.33(0.80 \text { to } \\
2.21)\end{array}$ & & & $\begin{array}{l}3.38(1.77 \text { to } \\
6.46)\end{array}$ & $\begin{array}{l}2.85 \text { (1.55 to } \\
5.22)\end{array}$ \\
\hline \multicolumn{8}{|c|}{ SASA! exposure } \\
\hline \multicolumn{8}{|c|}{ Reported exposure to SASA! } \\
\hline None & & & & & & & - \\
\hline $\begin{array}{l}\text { Low/ } \\
\text { moderate }\end{array}$ & & & & & & & $\begin{array}{l}2.08 \text { (1.02 to } \\
4.24)\end{array}$ \\
\hline High & & & & & & & $\begin{array}{l}6.45(2.35 \text { to } \\
17.74)\end{array}$ \\
\hline
\end{tabular}

*Adjusted for community as a fixed effect. SE calculated using cluster robust option.

CSA, child sexual abuse; IPV, intimate partner violence.

change roughly mirrors Latané and Darley's individual-level framework for understanding bystander actionthe Support phase specifically focuses on instilling community members with a sense of responsibility to act, equipping them with the skills to respond to women experiencing violence, and providing them with information on where they can refer women or men who need help. Second, as confirmed by qualitative research, individuals with personal motivation to act found themselves in an environment supportive of action, surrounded by others prepared to take (or at least condone) action to address VAW. ${ }^{50}$

It is interesting to note that, in SASA! communities, past year IPV experience/perpetration was less strongly associated with trying to help than lifetime IPV experience/perpetration was. It is possible that those currently experiencing IPV have similar motivations to intervene but less power, confidence or support with which to do so. Likewise, current perpetrators may be those men most resistant to change and harbouring the most regressive attitudes.

Attitudes towards the acceptability of IPV and whether it is okay for a woman to tell if she is experiencing violence were also strongly (and independently) related to propensity to try and help in SASA! communities. This is consistent with other research showing that less personal tolerance of IPV is associated with bystander action. ${ }^{26}$ Such attitudes likely increase the probability that the bystander interprets the event as a problem worthy of intervention, and motivate them to assume responsibility for taking action. ${ }^{1751}$ However, as discussed above, motivation may not be sufficient to promote action if other individual and contextual factors supportive of action are lacking-hence the more consistent associations in SASA! compared with control communities. This finding highlights the importance of changing attitudes and privacy norms around IPV, not just as a direct route to IPV prevention, but also to improve community responses to violence when it occurs. Proponents of bystander interventions highlight the cyclical nature of this association, with increased bystander action potentially feeding back into community-level norm change. ${ }^{1523}$

Among women in SASA! communities, ties to the community were associated with trying to help. This finding is consistent with evidence from research into school bullying $^{52} 53$ and general violence ${ }^{26}$ that shows associations between social capital (social support and community engagement) and increased likelihood of engaging in prosocial bystander behaviour. Research has shown that in communities where social capital and collective efficacy are high, community members are more likely to look out for each other and able to use the relationships they have to work collaboratively to prevent and respond to violence in their communities. ${ }^{54}$ Regarding the absence of such an association in control communities, we surmise that strong ties to the community might only increase the probability of trying to help if the community itself has norms sanctioning rather than condoning VAW. In SASA! communities where community-wide acceptance of IPV has decreased, a woman with stronger ties to her community will be more closely allied with norms that promote action against IPV, other individuals prepared to take action with her and sources of help to whom she can refer the couple involved. ${ }^{50}$ Indeed, the creation of an environment supportive of taking action is very much the focus of the Support and Action phases of the SASA! intervention. In control communities, conversely, strong ties to the community may just serve to reinforce acceptance and tolerance of IPV.

Finally, while SASA! is a community-level intervention and everyone in SASA! communities can be classified as 'exposed', levels of engagement with SASA! differed between community members. Within SASA! communities, propensity to act increased with higher reported exposure to SASA!. This result is encouraging, although not surprising. Individuals with higher exposure may 
Table 4 Multivariate models of factors associated with men trying to help when they see/hear IPV in their communities

Control communities

Model $1 \%$

$\mathrm{OR}^{\star}(95 \% \mathrm{Cl}) \quad \mathrm{OR}^{\star}(95 \% \mathrm{Cl})$
SASA! communities

\section{SASA! communities}

Model $3 \quad$ Model $1 \quad$ Model 2

$\mathrm{OR}^{*}(95 \% \mathrm{Cl})$

$\mathrm{OR}^{\star}(95 \% \mathrm{Cl}) \quad \mathrm{OR}^{\star}(95 \% \mathrm{Cl})$

Model 4

$\mathrm{OR}^{\star}(95 \% \mathrm{Cl})$

\section{Demographics \\ Age (years)}

$\begin{array}{llllllll}18-24 & - & - & - & - & - & - & - \\ \text { 25-34 } & 1.68(0.93 \text { to } & 1.68(0.93 \text { to } & 1.47(0.77 \text { to } & 1.66(0.94 \text { to } & 1.72(0.99 \text { to } & 1.31(0.72 \text { to } & 1.37(0.72 \text { to } \\ & 3.03) & 3.04) & 2.86) & 2.93) & 2.99) & 2.37) & 2.61) \\ 35-49 & 1.19(0.54 \text { to } & 1.20(0.55 \text { to } & 1.00(0.42 \text { to } & 1.63(0.62 \text { to } & 1.72(0.65 \text { to } & 0.99(0.38 \text { to } & 1.05(0.38 \text { to } \\ & 2.61) & 2.62) & 2.37) & 4.32) & 4.51) & 2.62) & 2.87)\end{array}$

Relationship duration

$\begin{array}{llllllll}\begin{array}{l}\text { Not in } \\ \text { relationship }\end{array} & - & - & - & - & - & - \\ \text { 0-3 years } & 2.18(1.32 \text { to } & 2.22(1.34 \text { to } & 1.75(0.92 \text { to } & 1.51(0.90 \text { to } & 1.47(0.86 \text { to } & 1.57(0.80 \text { to } & 1.38(0.74 \text { to } \\ & 3.59) & 3.67) & 3.32) & 2.54) & 2.51) & 3.10) & 2.58) \\ >3 & \text { years } & 3.30(1.74 \text { to } & 3.31(1.73 \text { to } & 2.80(1.31 \text { to } & 2.24(1.47 \text { to } & 2.11(1.38 \text { to } & 2.39(1.23 \text { to } 1.88(0.99 \text { to } \\ & 6.26) & 6.35) & 5.98) & 3.42) & 3.24) & 4.67)\end{array}$

Currently employed

$\begin{array}{lllllllll}\text { No } & - & - & - & - & - & - \\ \text { Yes } & 1.39(0.63 \text { to } & 1.38(0.61 \text { to } & 1.43(0.60 \text { to } & 0.53(0.28 \text { to } & 0.54(0.29 \text { to } & 0.58(0.26 \text { to } & 0.56(0.26 \text { to } \\ & 3.07) & 3.08) & 3.38) & 0.98) & 1.01) & 1.29) & 1.18)\end{array}$

Childhood experiences of abuse

Any abuse-related experience as a child (witnessed IPV, badly beaten or CSA)

\begin{tabular}{|c|c|c|c|c|c|}
\hline No & - & - & - & - & - \\
\hline Yes & $\begin{array}{l}0.75 \text { (0.50 to } \\
1.12)\end{array}$ & $\begin{array}{l}0.77 \text { (0.50 to } \\
1.18)\end{array}$ & $\begin{array}{l}1.56 \text { (0.95 to } \\
2.57)\end{array}$ & $\begin{array}{l}1.22(0.77 \text { to } \\
1.94)\end{array}$ & $\begin{array}{l}1.29(0.80 \text { to } \\
2.09)\end{array}$ \\
\hline
\end{tabular}

Ties to community

How long lived in the community (years)

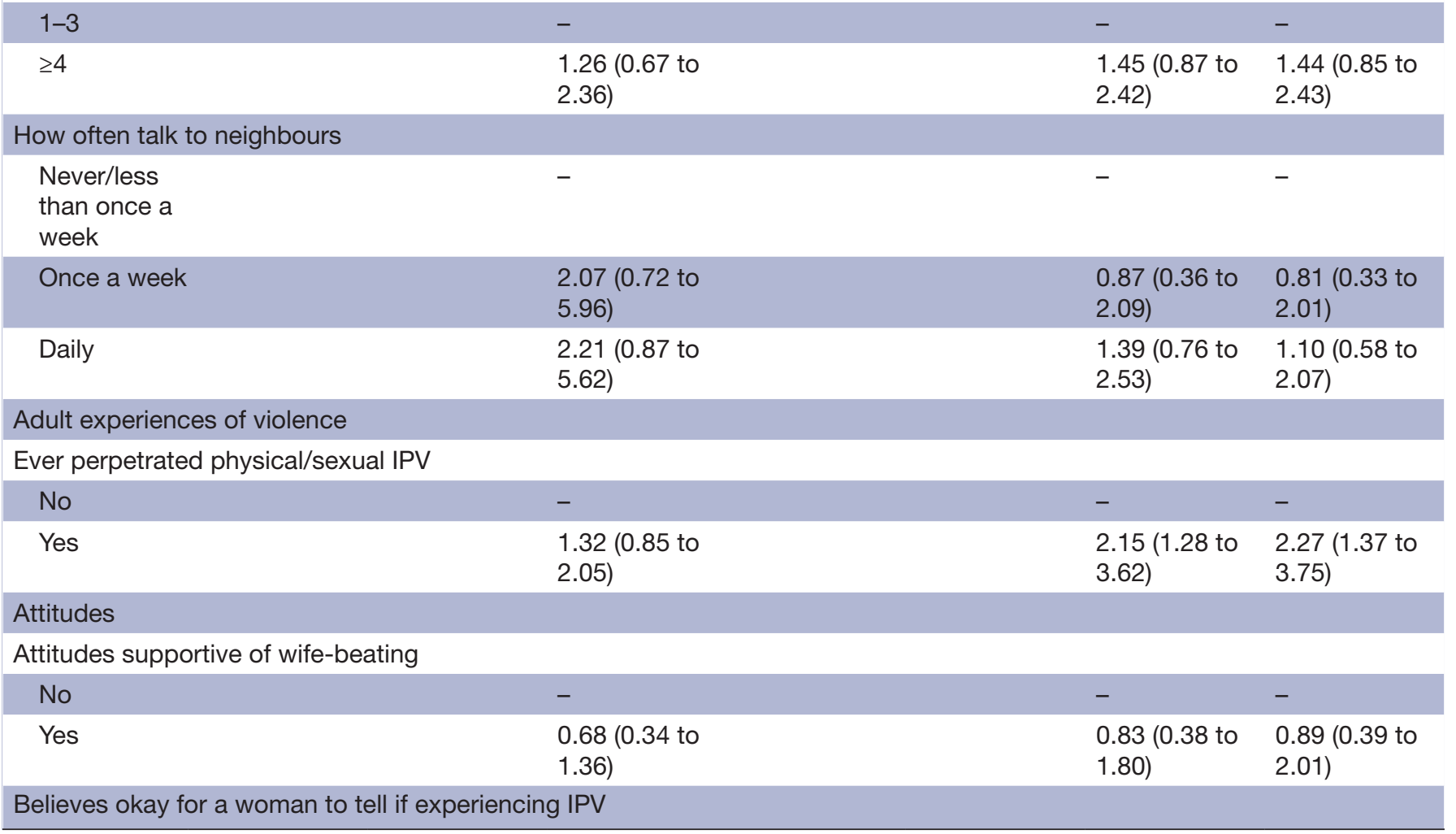

Continued 
Table 4 Continued

\begin{tabular}{|c|c|c|c|c|c|c|c|}
\hline & \multicolumn{3}{|c|}{ Control communities } & \multicolumn{4}{|c|}{ SASA! communities } \\
\hline & $\begin{array}{l}\text { Model } 1 \\
\text { OR* }(95 \% \text { Cl) }\end{array}$ & $\begin{array}{l}\text { Model } 2 \\
\text { OR* }(95 \% \mathrm{Cl})\end{array}$ & $\begin{array}{l}\text { Model } 3 \\
\text { OR }^{\star}(95 \% \text { Cl) }\end{array}$ & $\begin{array}{l}\text { Model } 1 \\
\text { OR* }(95 \% \mathrm{Cl})\end{array}$ & $\begin{array}{l}\text { Model } 2 \\
\text { OR }^{\star}(95 \% \mathrm{Cl})\end{array}$ & $\begin{array}{l}\text { Model } 3 \\
\text { OR }^{\star}(95 \% \text { Cl) }\end{array}$ & $\begin{array}{l}\text { Model } 4 \\
\text { OR }^{\star}(95 \% \mathrm{Cl})\end{array}$ \\
\hline Yes & & & $\begin{array}{l}1.92(1.28 \text { to } \\
2.89)\end{array}$ & & & $\begin{array}{l}2.71(1.29 \text { to } \\
5.70)\end{array}$ & $\begin{array}{l}2.26(0.95 \text { to } \\
5.40)\end{array}$ \\
\hline \multicolumn{8}{|c|}{ SASA! exposure } \\
\hline None & & & & & & & - \\
\hline $\begin{array}{l}\text { Low/ } \\
\text { moderate }\end{array}$ & & & & & & & $\begin{array}{l}3.29(1.51 \text { to } \\
7.16)\end{array}$ \\
\hline High & & & & & & & $\begin{array}{l}5.83(2.49 \text { to } \\
13.64)\end{array}$ \\
\hline
\end{tabular}

*Adjusted for community as a fixed effect. SE calculated using cluster robust option.

CSA, child sexual abuse; IPV, intimate partner violence.

experience more profound attitudinal change (data not shown) which likely instils in them a greater motivation to act when they witness IPV. Engagement with SASA! also likely increases their skills and sense of self-efficacy, whereby they know which actions are likely to be helpful and believe that they can make a difference to the situation. Furthermore, intervention engagement will engender stronger links with others in the community committed to preventing VAW, thereby providing individuals with a network of others they can act with, as well as a general sense that their community is supportive of action. Reverse causality is also a possibility, whereby those most interested in preventing IPV proactively seek out engagement with SASA!.

This study has several strengths. We analysed data from men and women on a broad range of personal characteristics and experiences. Furthermore, having data from a CRT has enabled us to compare the profiles of helpers between intervention and control communities, allowing important insights into how (and among whom) SASA! strengthened community responses to IPV.

The study also has a number of limitations. Under-reporting of IPV is a concern in such studies. ${ }^{556}$ Measurement bias was minimised through the use of widely used standardised questions to measure IPV (and anonymous cards for men), administered by interviewers who had undergone 3 weeks of training on conducting surveys relating to IPV. Nevertheless, under-reporting could still have occurred, particularly among men in intervention communities. If social desirability bias also led SASA! community members to over-report their own helping behaviours, we may have underestimated the association between IPV perpetration and helping among men in SASA! communities. Despite this, we still observed sizeable associations (similar to those for women's IPV experience).

Recall bias is also possible, with those who experience or perpetrate violence potentially conceptualising or recalling trying to help differently from those with no personal history of IPV. If this were the case, however, we might expect recent IPV to be more strongly associated with trying to help than lifetime IPV experience/perpetration. In fact, we observe the reverse.

Social desirability bias could also have caused individuals in SASA! communities to exaggerate their actions, thus causing us to overestimate the association between SASA! exposure and reported helping behaviour. However, it is encouraging to note that similar patterns of improved community responses in SASA! communities have also been reported by women experiencing IPV. ${ }^{10}$

With cross-sectional data, it is not possible to establish the direction of an association. Nevertheless, we can be confident that some exposures (demographics and lifetime or childhood experiences of violence) at least preceded the outcome even if the associations were not causal. It would however be prudent to interpret results as describing who is most likely to intervene rather than explaining why people intervene.

It is also worth noting that this paper focuses on 'trying to help' rather than the types of action taken or their effectiveness. Furthermore, the outcome in this analysis relates to situations where the respondent has seen or heard IPV occurring. Those who attempt to help when they witness violence (where there may be more immediate safety concerns associated with intervening) may differ in profile from those who try to help a woman who discloses experiences of IPV or a man who asks for their support to stop using violence. Further research could help shed light on variation in the profiles of helpers and the types of help offered in different scenarios.

\section{CONCLUSIONS}

These findings are novel as they provide evidence from a community sample and low-income setting on which community members are most likely to intervene when 
they witness IPV. Furthermore, we explored which factors predisposed people to help in the presence and absence of a violence prevention intervention. While other (although few) studies have measured the impact of 'bystander programmes' on rates of intervention, we do not know of other studies which have examined how prevention programmes may influence the profile of who intervenes. Our findings suggest that certain individuals may have a latent predisposition to intervene which SASA! taps into and nurtures-equipping them with the skills, confidence, sense of responsibility and supportive environment required to translate inclination into action. That factors appear to work synergistically to promote community responses lends further support to community mobilisation approaches that target multiple layers of risk factors and create environments intolerant of IPV. Against this backdrop, attitudinal change, long championed as a means to reduce IPV perpetration, has also been associated with improved community responses to IPV, vital to cementing norm change and intervention impact in the longer term.

Finally, evaluations of community mobilisation programmes, focusing as they often do on 'impact', tend to conceptualise community members as beneficiaries of the intervention. It is important to remember, however, that community members are also the implementers and enablers of community mobilisation. In the case of SASA!, an intervention to reduce VAW, it is heartening to see that those who are arguably the largest beneficiaries of the intervention-those with direct personal experience of IPV - are also those most likely to be an active part of the solution.

Acknowledgements Many people, both within and outside these institutions, have helped to make this study possible. We would like to express our sincere thanks to the staff of Raising Voices and CEDOVIP who have been responsible for the design and implementation of the SASA! intervention and also provided invaluable support to the research process by building relationships with community leaders in order to obtain consent for the study. Their participation in the design and translation of study tools, interviewer training, and ongoing monitoring and evaluation of the study has also been of fundamental importance. We are indebted to the hard work and dedication of the researchers and supervisors who collected the data, without whom this study would not have been possible. We are also grateful to the women and men who agreed to participate in this study and were willing to share their time and stories with us. We would especially like to acknowledge all of the CEDOVIP staff and community activists, who through commitment and dedication have worked hard to prevent violence in their communities.

Contributors CW, LM and TM were the principal investigators on the SASA! study, responsible for the overall conceptualisation, design and management of the study. TA was responsible for major aspects of study design, sampling, development of research instruments, interviewer training and supervision of the quantitative survey. TA and SN formulated the objectives and conceptual framework for this paper. TA drafted the manuscript and conducted the statistical analysis for this paper. All authors have contributed to the writing of this paper, offering substantial edits and comments to the original draft. All have read and approved the final version.

Funding This research was funded by Irish Aid, the Sigrid Rausing Trust, 3ie (International Initiative for Impact Evaluation), an anonymous donor, AusAID and the Stephen Lewis Foundation. Irish Aid, the American Jewish World Service, HIVos and the NoVo Foundation supported the implementation and monitoring of SASA! in the study communities. The analysis and writing of this article were supported by an anonymous donor. The study sponsors had no role in the study design, data collection, analysis and interpretation of the data, the writing of this report, or the decision to submit this paper for publication. The views expressed are those of the authors alone.

Competing interests LM is Co-Director of Raising Voices and designed the SASA! intervention. TM is the Director of CEDOVIP and in charge of the implementation of the SASA! intervention. They have played a central role in ensuring the appropriate conceptualisation and implementation of the evaluation, including the topics covered in the study questionnaire, the implementation of the fieldwork and ensuring the provision of support to women requesting assistance. They have had no involvement in the randomisation of matched community pairs, no direct involvement in data collection for the CRT and no involvement with the data analysis. SN joined Raising Voices as the Learning Coordinator after the completion of the CRT. LM, TM and SN have input into the interpretation of the findings. The other authors declare that they have no competing interests.

\section{Patient consent for publication Obtained.}

Ethics approval The study received ethical approval from institutional review boards at the London School of Hygiene and Tropical Medicine (UK) (ref 5210), Makerere University (Uganda) (ref 2007-101) and the Uganda National Council for Science and Technology (SS 2048). The study conformed to the principles embodied in the Declaration of Helsinki.

Provenance and peer review Not commissioned; externally peer reviewed.

Data sharing statement Survey tools are available from the London School of Hygiene and Tropical Medicine data repository via the following link: http:// datacompass.Ishtm.ac.uk/19/. Applications to use data from the follow-up survey and limited data from the baseline survey can be submitted via the same link.

Open access This is an open access article distributed in accordance with the Creative Commons Attribution Non Commercial (CC BY-NC 4.0) license, which permits others to distribute, remix, adapt, build upon this work non-commercially, and license their derivative works on different terms, provided the original work is properly cited, appropriate credit is given, any changes made indicated, and the use is non-commercial. See: http://creativecommons.org/licenses/by-nc/4.0/

\section{REFERENCES}

1. Devries KM, Mak JY, García-Moreno C, et al. Global health. The global prevalence of intimate partner violence against women. Science 2013;340:1527-8.

2. Heise LL, Kotsadam A. Cross-national and multilevel correlates of partner violence: an analysis of data from population-based surveys. Lancet Glob Health 2015;3:e332-e340.

3. World Health Organization, London School of Hygiene and Tropical Medicine, South African Medical Research Council. Global and regional estimates of violence against women: prevalence and health effects of intimate partner violence and non-partner sexual violence. Geneva: World Health Organization, 2013.

4. Ellsberg M, Arango DJ, Morton M, et al. Prevention of violence against women and girls: what does the evidence say? Lancet 2015;385:1555-66.

5. Pronyk PM, Hargreaves JR, Kim JC, et al. Effect of a structural intervention for the prevention of intimate-partner violence and HIV in rural South Africa: a cluster randomised trial. Lancet 2006;368:1973-83

6. Jewkes R, Nduna M, Levin J, et al. Impact of stepping stones on incidence of HIV and HSV-2 and sexual behaviour in rural South Africa: cluster randomised controlled trial. BMJ 2008;337:a506.

7. Hossain M, Zimmerman C, Kiss L, et al. Working with men to prevent intimate partner violence in a conflict-affected setting: a pilot cluster randomized controlled trial in rural Côte d'Ivoire. BMC Public Health 2014;14:339.

8. Heise L. What works to prevent partner violence? An evidence overview. London: STRIVE Research Consortium, 2011.

9. Heise LL. Violence against women: an integrated, ecological framework. Violence Against Women 1998;4:262-90.

10. Abramsky T, Devries K, Kiss L, et al. Findings from the SASA! Study: a cluster randomized controlled trial to assess the impact of a community mobilization intervention to prevent violence against women and reduce HIV risk in Kampala, Uganda. BMC Med 2014;12:122.

11. Wagman JA, Gray RH, Campbell JC, et al. Effectiveness of an integrated intimate partner violence and HIV prevention intervention in Rakai, Uganda: analysis of an intervention in an existing cluster randomised cohort. Lancet Glob Health 2015;3:e23-e33. 
12. Planty M. Bureau of Justice Statistics Special Report: Thirdparty involvement in violent crime, 1993-99. Washington DC: US Department of Justice, 2002

13. Hamby S, Weber MC, Grych J, et al. What difference do bystanders make? The association of bystander involvement with victim outcomes in a community sample. Psychol Violence 2016;6:91-102.

14. Banyard VL, Plante EG, Moynihan MM. Bystander education: Bringing a broader community perspective to sexual violence prevention. J Community Psychol 2004;32:61-79.

15. Fenton RA, Mott HL, McCartan K, et al. A review of evidence for bystander intervention to prevent sexual and domestic violence in universities. Bristol: Public Health England, 2016.

16. Abramsky T, Devries KM, Michau L, et al. The impact of SASA!, a community mobilisation intervention, on women's experiences of intimate partner violence: secondary findings from a cluster randomised trial in Kampala, Uganda. J Epidemiol Community Health 2016;70:818-25.

17. Latané B, Darley JM. The unresponsive bystander : why doesn't he help? Englewood Cliffs. 131. Prentice-Hall, 1970.

18. Kelly JG. Becoming ecological : an expedition into community psychology. 318. New York; Oxford: Oxford University Press, 2006.

19. Banyard VL. Who will help prevent sexual violence: Creating an ecological model of bystander intervention. Psychol Violence 2011;1:216-29.

20. Banyard V, Weber MC, Grych J, et al. Where are the helpful bystanders? Ecological niche and victims' perceptions of bystander intervention. J Community Psychol 2016;44:214-31.

21. McCauley HL, Tancredi DJ, Silverman JG, et al. Gender-equitable attitudes, bystander behavior, and recent abuse perpetration against heterosexual dating partners of male high school athletes. Am J Public Health 2013;103:1882-7.

22. Menning CL. Unsafe at any house?: attendees' perceptions of microlevel environmental traits and personal safety at fraternity and nonfraternity parties. J Interpers Violence 2009;24:1714-34.

23. Banyard VL. The Promise of a Bystander Approach to Violence Prevention, in Toward the Next Generation of Bystander Prevention of Sexual and Relationship Violence. New York: Springer International Publishing, 2015.

24. Breaking the Cycle. Bystander Survey. Opinion Research Corporation, 2006.

25. Banyard VL. Measurement and correlates of prosocial bystander behavior: the case of interpersonal violence. Violence Vict 2008;23:83-97.

26. Frye $\mathrm{V}$. The informal social control of intimate partner violence against women: Exploring personal attitudes and perceived neighborhood social cohesion. J Community Psychol 2007;35:1001-18.

27. Banyard VL, Plante EG, Moynihan MM. Rape Prevention Through Bystander Education: Bringing a Broader Community Perspective to Sexual Violence Prevention. Washington DC, 2005.

28. Stürmer S, Snyder M, Omoto AM. Prosocial emotions and helping: the moderating role of group membership. J Pers Soc Psychol 2005;88:532-46.

29. Nabi RL, Horner JR, Homer J. Victims with voices: How abused women conceptualize the problem of spousal abuse and implications for intervention and prevention. J Fam Violence 2001:16:237-53.

30. Chabot HF, Tracy TL, Manning CA, et al. Sex, attribution, and severity influence intervention decisions of informal helpers in domestic violence. J Interpers Violence 2009;24:1696-713.

31. Nicksa SC. Bystander's willingness to report theft, physical assault, and sexual assault: the impact of gender, anonymity, and relationship with the offender. $J$ Interpers Violence 2014;29:217-36.

32. West $A$, Wandrei ML. Intimate partner violence - A model for predicting interventions by informal helpers. Journal of Interpersonal Violence 2002;17:972-86.

33. Shotland RL, Stebbins CA. Bystander Response to Rape: Can A Victim Attract Help?1. J Appl Soc Psychol 1980;10:510-27.
34. Green DP, Wilke A, Cooper J. Silence Begets Violence: A mass media experiment to prevent violence against women in rural Uganda. Newhaven, CT: Innovations for Poverty, 2018.

35. Powell A. Review of bystander approaches in support of preventing violence against women. Victoria, Australia: Carlton, 2011.

36. Storer HL, Casey E, Herrenkohl T. Efficacy of Bystander Programs to Prevent Dating Abuse Among Youth and Young Adults: A Review of the Literature. Trauma Violence Abuse 2016;17:256-69.

37. Banyard VL, Moynihan MM, Plante EG. Sexual violence prevention through bystander education: An experimental evaluation. $J$ Community Psychol 2007;35:463-81.

38. Moynihan MM, Banyard VL, Arnold JS, et al. Engaging intercollegiate athletes in preventing and intervening in sexual and intimate partner violence. J Am Coll Health 2010;59:197-204.

39. Coker AL, Cook-Craig PG, Williams CM, et al. Evaluation of Green Dot: an active bystander intervention to reduce sexual violence on college campuses. Violence Against Women 2011;17:777-96.

40. Gidycz CA, Orchowski LM, Berkowitz AD. Preventing sexual aggression among college men: an evaluation of a social norms and bystander intervention program. Violence Against Women 2011:17:720-42.

41. Coker AL, Bush HM, Cook-Craig PG, et al. RCT Testing Bystander Effectiveness to Reduce Violence. Am J Prev Med 2017;52:566-78.

42. Salazar LF, Vivolo-Kantor A, Hardin J, et al. A web-based sexual violence bystander intervention for male college students: randomized controlled trial. J Med Internet Res 2014;16:e203.

43. Jouriles EN, Krauss A, Vu NL, et al. Bystander programs addressing sexual violence on college campuses: A systematic review and meta-analysis of program outcomes and delivery methods. J Am Coll Health 2018;66:457-66.

44. Michau L. The SASA ! Activist Kit for Preventing Violence against Women and HIV. Kampala, Uganda: Raising Voices, 2008.

45. Prochaska JO, DiClemente CC, Norcross JC. In search of how people change. Applications to addictive behaviors. Am Psychol 1992;47:1102-14.

46. Abramsky T, Devries K, Kiss L, et al. A community mobilisation intervention to prevent violence against women and reduce HIV/ AIDS risk in Kampala, Uganda (the SASA! Study): study protocol for a cluster randomised controlled trial. Trials 2012;13:96.

47. Watts C, Heise LL, Ellsberg M, et al. Putting women's safety first: ethical and safety recommendations for research on domestic violence against women. Geneva: World Health Organization, 1999.

48. Garcia-Moreno CJ, Ellsberg M, Heise LL, et al. WHO Multi-Country Study on Womens Health an Domestic Violence against women. Geneva: WHO, 2005.

49. Deitz SR, Blackwell KT, Daley PC, et al. Measurement of empathy toward rape victims and rapists. J Pers Soc Psychol 1982;43:372-84.

50. Kyegombe N, Starmann E, Devries KM, et al. 'SASA! is the medicine that treats violence'. Qualitative findings on how a community mobilisation intervention to prevent violence against women created change in Kampala, Uganda. Glob Health Action 2014;7:25082.

51. Berkowitz A. Response Ability: A complete Guide to Bystander Intervention. Chicago: Beck and Company, 2009.

52. Evans CB, Smokowski PR. Prosocial bystander behavior in bullying dynamics: Assessing the impact of social capital. J Youth Adolesc 2015;44:2289-307.

53. Jenkins LN, Fredrick SS. Social capital and bystander behavior in bullying: Internalizing problems as a barrier to prosocial intervention. $J$ Youth Adolesc 2017;46:757-71.

54. Edwards KM, Mattingly MJ, Dixon KJ, et al. Community matters: intimate partner violence among rural young adults. Am J Community Psychol 2014;53(1-2):198-207.

55. Ellsberg M, Heise L, Peña R, et al. Researching domestic violence against women: methodological and ethical considerations. Stud Fam Plann 2001;32:1-16.

56. Ellsberg M, Heise L. The Challenge of Defining and Measuring Violence in Quantitative Research, in Researching Violence Against Women: A Practical Guide for Researchers and Activists. Washington DC: World Health Organisation, PATH, 2005. 